\title{
Difusão de políticas sob a abordagem territorial: uma análise dos pontos sensíveis de replicação do Programa Leader europeu para o contexto latino-americano
}

\author{
João Paulo Ghesti \\ Universidade de Brasilia (UnB) \\ Sandro Pereira Silva \\ Instituto de Pesquisa Econômica Aplicada (Ipea)
}

Este artigo visa proceder a uma análise das dimensões sensíveis do Programa Leader no que diz respeito ao processo de transferência institucional da abordagem territorial contida nesse Programa. À luz da literatura de policy transfer, problematiza-se sobre a viabilidade de sua utilização como referência normativa para a implementação de programas metodologicamente similares em países da América Latina. Assim, este texto contribui para o debate sobre os aspectos do processo de difusão de políticas públicas de díficil equacionamento em contextos políticos e institucionais diversos daquele de onde a experiência se originou.

Palavras-chave: políticas públicas - transferência, cooperação internacional, planejamento territorial, implementação - programa, américa latina

[Artigo recebido em 1ㅇ de agosto de 2017. Aprovado em 20 de setembro de 2018.] 
Difusión de políticas con enfoque territorial: un análisis de los puntos sensibles de replicación del Programa Leader europeo para el contexto latinoamericano

Este artículo tiene por objeto proceder a un análisis de las dimensiones sensibles del programa Leader en lo que se refiere al proceso de transferencia institucional del enfoque territorial contenido en este programa. A la luz de la literatura de policy transfer, se problematiza sobre la viabilidad de su utilización como referencia normativa para la implementación de programas metodológicamente similares en países de América Latina. Así, este texto contribuye al debate sobre los aspectos del proceso de difusión de políticas públicas de difícil concertación en contextos políticos e institucionales diversos a aquel donde la experiencia se originó.

Palabras clave: políticas públicas - transferencia, cooperación internacional, planificación territorial, implementación - programa, américa latina

Policy diffusion with territorial approach: an analysis of sensitive points for replication of the European Leader Program for the latin american context

This article aims at analyzing the sensitive dimensions of the Leader Program with regard to the process of institutional transfer of its territorial approach. In light of the transfer policy of literature, it discusses about the feasibility of its use as a normative reference for the implementation of methodologically similar programs in Latin America. Thus, this text contributes to the debate on the aspects of the process of diffusion of public policies of difficult concertation in political and institutional contexts different from the one where the experience originated.

Keywords: public policies - transfer, international cooperation, territorial planning, implementation - program, latin america 


\section{Introdução}

O debate em torno de políticas públicas planejadas a partir de uma abordagem territorial ganhou relativo destaque nos últimos anos, tanto no meio acadêmico como no meio político e governamental. Em suma, trata-se de ações de governo que levam em conta as especificidades de diferentes recortes espaciais, no intuito de valorizar suas potencialidades econômicas com o envolvimento dos atores locais, tendo como pano de fundo a busca por um desenvolvimento nacional mais inclusivo e equitativo (SILVA, 2012; 2013a).

No contexto latino-americano, vários países criaram programas próprios e estruturas institucionais específicas para sua implementação, sobretudo para políticas de desenvolvimento rural. Essas políticas baseadas em estratégias de planejamento territorial tiveram como referência o programa Ligações entre Ações do Desenvolvimento da Economia Rural (Leader), lançado na União Europeia (UE) em 1991 para ser o principal instrumento de estímulo ao desenvolvimento das áreas rurais europeias (FAVARETO, 2010; PERAFÁN, 2007; TORRES; MACÍAS, 2009; SILVA, 2013b).

Embora a abordagem territorial seja apontada como uma forma inovadora de se estabelecer relações políticas de planejamento da ação governamental entre Estado e sociedade, alguns questionamentos podem ser levantados sobre a trajetória de elaboração e implementação de programas expressos sob tais estratégias na América Latina. Ainda mais pelo fato de sua principal referência normativa ser derivada de um programa vindo de um contexto econômico, social e regional tão distinto como o europeu, o que torna mais complexo seu processo de tradução para as realidades receptoras.

Isto posto, este trabalho tem como objetivo proceder a uma análise das dimensões críticas a serem consideradas no processo de transferência do modelo de abordagem territorial (AT), proposto pelo Programa Leader na UE, para países da América Latina, problematizando sobre a viabilidade de sua utilização como referência normativa. Buscou-se, com isso, construir um quadro analítico cujo grau de generalização poderá resultar, juntamente com o conceito apresentado de "espraiamento internacional de lições", em uma contribuição relevante ao campo de estudos sobre policy transfer e lesson drawing, ao lançar luz sobre as particularidades e as restrições ao processo de transferência de políticas públicas entre contextos institucionais distintos.

O artigo está organizado em seis seções. Dando segmento a esta introdução, a seção dois apresenta uma breve síntese do debate sobre policy transfer e lesson drawing na literatura, além de situar as categorias definidas para a análise. Na seção 
três são descritos alguns pontos fundamentais da abordagem territorial presente no Programa Leader e como se iniciou seu processo de difusão para a América Latina. Posteriormente, são debatidas cada uma das sete categorias do modelo analítico escolhido, conforme proposto por Rose (1993). Após os apontamentos problematizados a partir dessas categorias, é apresentada na seção seis uma síntese na qual se insere o conceito de "espraiamento internacional de lições", que se refere, nesse caso, à disseminação generalizada de lições extraídas de outros contextos nacionais que se mostram racionalmente atraentes e justificáveis em curto prazo, mas cuja eficácia para implementação do seu conteúdo a médio e longo prazos pode ser bastante comprometida caso não sejam levadas em consideração algumas questões fundamentais para sua fungibilidade, conforme debatido neste trabalho. Por fim, são tecidas algumas considerações conclusivas.

\section{Processos de difusão de política pública}

Os estudos situados no campo da difusão e transferência de políticas (policy transfer) se referem a um processo por meio do qual o conhecimento sobre políticas, arranjos administrativos, instituições e ideias em um contexto nacional (passado ou presente) é usado como referência normativa para a implementação de seu conteúdo em outro cenário (Dolowitz; MARSH, 2000). Essencialmente, trata-se de uma estratégia desenvolvida em algum lugar que é tomada e aplicada em outro contexto político.

Embora grande parte da literatura trate do envolvimento de agências estatais nas transferências, abordagens mais recentes têm assimilado que o processo pode envolver também entidades não-estatais, do mesmo modo que pode ocorrer em múltiplos níveis de coordenação em um mesmo país. Redes globais e transnacionais de transferência frequentemente possuem grande participação nesse processo, além de distintas categorias de atores políticos, como: políticos eleitos, partidos, funcionários públicos, grupos de pressão, especialistas, corporações transnacionais, grupos de reflexão (think tanks) e ONGs (DOLOWITZ; MARSH, 2000).

Nessa perspectiva, o processo de transferência pode envolver uma diversidade de interações entre: o objeto transferido; as estratégias e os processos na transferência de informações de um ambiente para outro; os agentes estatais e não-estatais; e as motivações para a transferência (DolowitZ, 2003; BISSELL; LEE; FREEMAN, 2011).

A própria globalização - e a abertura internacional dos mercados que lhe é consequente - tem atuado como um elemento facilitador desse mecanismo, ao aumentar as oportunidades, os espaços e a velocidade de circulação de informações políticas. Reciprocamente, o processo de policy transfer facilita a globalização a 
partir do compartilhamento de referenciais e arranjos institucionais entre contextos nacionais distintos, principalmente via a criação de novas estruturas regionais como a União Europeia - e o ativismo das organizações de governança internacional - como a Organização para a Cooperação e Desenvolvimento Econômico (OCDE), o Fundo Monetário Internacional (FMI) e a Organização das Nações Unidas (ONU). Tais organizações desempenham um papel crescente na disseminação de ideias, programas e instituições ao redor do globo, ao influenciarem diretamente os formuladores nacionais de políticas por meio de seus protocolos para concessão de empréstimo, ou, indiretamente, através da "filtragem" e disseminação de informações em suas conferências e relatórios (LADI, 1999).

No entanto, processos de transferência e difusão de políticas exigem cuidados teóricos e práticos muitas vezes desconsiderados pelos atores responsáveis. Dolowitz e Marsh (2000), por exemplo, identificaram três aspectos que exercem efeito significativo no fracasso de um processo de policy transfer: i) o conhecimento insuficiente por parte do país importador (uninformed transfer); ii) o conhecimento insuficiente sobre a política/instituição, sua trajetória e seu funcionamento no país de origem (incomplete transfer); e iii) a atenção dada insuficientemente às diferenças entre os contextos econômicos, social, político e ideológico entre os países (inappropriate transfer). Portanto, pode ocorrer que os elementos cruciais que fazem com que determinada política ou instituição funcione em seu país de origem não sejam passíveis de serem transferidos para seu novo "território de incidência" (SILVA, 2014), o que compromete seriamente sua capacidade de efetivação.

Newmark (2002) chamou a atenção para outro aspecto relevante. Para ele, policy transfersempre envolve difusão, ao passo que difusão não necessariamente indica a ocorrência de policy transfer, pois implica necessariamente um caso no qual os agentes estão cientes do uso de uma política adotada em outros contextos. Ou seja, há uma exigência do critério de intencionalidade para o processo ser reconhecido como tal.

Outro conceito relevante nesse tipo de debate é o de "delineamento de lições" (lesson drawing). Ele se vale de uma perspectiva mais particular de difusão e transferência, abrangendo (em ordem descendente) emulação, hibridização, síntese e/ou inspiração a partir de observações empíricas de uma atividade prática, da qual lições são tiradas como ferramentas para orientarem a ação. Dessa forma, o lesson drawing pode ser entendido como um mecanismo peculiar de policy transfer que implica uma assimilação cognitiva de instituições, em que uma matriz de concepções e procedimentos para a implantação de uma política pública é traduzida e preparada para incidir em outro contexto institucional. 
Nesse sentido, ele consiste em um aprendizado que os atores envolvidos desejam obter, visando a alguma vantagem percebida ao implementar determinada política (CARVALHO, 2012).

Segundo Rose (1993), a difusão de políticas por lesson drawing envolve diferentes etapas em sua operacionalização, por se tratar de um processo no qual o conhecimento sobre um programa em um país é aplicado no desenho de um novo programa em outro. Cada etapa irá determinar então o grau de "fungibilidade" de uma política ou instituição, isto é, mobilidade, adaptabilidade ou transferibilidade de uma lição entre contextos institucionais diferentes. Essas etapas referem-se a contingências que abrangem, por exemplo, uma análise de quais circunstancias e em que grau um programa que funciona em um lugar poderá funcionar em outro.

Para a análise do potencial de fungibilidade de uma instituição, Rose (1993) propôs sete categorias: i) singularidade: quanto menos elementos singulares um programa apresentar, mais fungível será esse programa; ii) instituições: quanto mais substituíveis forem as instituições envolvidas na execução de um programa, mais fungível ele será; iii) recursos: quanto maior for a equivalência de recursos entre governos, maior será a fungibilidade de um programa; iv) complexidade: quanto mais simples for a estrutura de causa-e-efeito de um programa, mais fungível ele será; v) mudanças: quanto menor for a escala de mudanças resultante da adoção de um programa, mais fungível ele será; vi) interdependência: quanto maior for a interdependência entre programas adotados em jurisdições diferentes, mais fungível será o impacto de um programa; e vii) valores: quanto maior for a consistência entre os valores dos formuladores de políticas públicas e os valores subjacentes a um programa, maior será a fungibilidade desse programa. Assim, o lesson drawing é uma atividade de descrição do tipo causa-e-efeito sobre um conjunto de ações que os governos podem considerar à luz da experiência estrangeira, com a realização de prescrições positivas sobre o que deveria ser feito e prescrições negativas em termos de não emulação de programas.

A partir desses recursos analíticos apresentados, a seção seguinte traz uma análise em abstrato do modelo Leader e sua utilização como referência normativa para a implementação de programas baseadas na abordagem territorial em países da América Latina.

\section{A estratégia do programa Leader}

Em 1991, a União Europeia, convencida da necessidade do incremento na competitividade das áreas rurais e considerando o desenvolvimento rural essencialmente como territorial, lançou a "Leader Community Iniciative" como 
parte de uma metodologia de desenvolvimento integrado, inclusive com o financiamento e incentivo a atividades não agrícolas, com o propósito de promover a redução das disparidades regionais (HESPANHOL; NEVES NETO, 2014). Essa iniciativa objetivava realizar experimentações em ações locais (territorial-based), de pequena escala, criadas e executadas por atores locais, usando o potencial endógeno de cada território, mas também com o estabelecimento de parcerias e a formação de redes juntamente com outros atores estrategicamente relevantes. Por isso, sua operacionalização deve ocorrer por meio do planejamento e da execução de projetos prioritários com base em uma estrutura política de participação social ascendente (bottom-up) em seus "territórios de incidência" (SILVA, 2013a; 2013b). Todos esses pontos constituem a base da AT que caracteriza o programa Leader. Se resultassem bem-sucedidas, essas iniciativas deveriam ser transferidas a outros territórios (CE, 2006).

O programa proporcionou um novo olhar para o mundo rural europeu, dando visibilidade às experiências existentes e destacando seu potencial de dinamização das economias territoriais. Como lições apreendidas, a OCDE (2003) destacou que a identidade local/territorial é o cerne de uma estratégia de desenvolvimento rural, e que os agentes locais estão em melhor posição para "imaginar" um futuro para as áreas rurais.

Uma característica importante da abordagem Leader se baseia na construção de parcerias locais entre os setores público e privado, denominada Grupos de Ação Local (GAL). Eles são responsáveis pela tarefa de identificar e aplicar uma estratégia de desenvolvimento territorial, tomar decisões sobre a atribuição de recursos financeiros e acompanhar projetos aprovados. Dados os trunfos e as dificuldades próprias a cada território, pode-se dizer que os GALs adotaram uma gama de estratégias, envolvendo: diversificação agrícola, agroturismo, agroindustrialização e valorização de produtos locais/tradicionais, serviços de proximidade etc. (JoUEN, 2001). As imposições para a realização das parcerias referem-se à exigência de representação local de, pelo menos, por $50 \%$ de associações do setor privado, e à participação dos agentes locais na tomada de decisões quanto à estratégia e seleção das prioridades a serem adotadas em sua zona (CE, 2006).

A abordagem ganhou adeptos para além do círculo de seus beneficiários e inspirou por vezes outras políticas regionais na Europa, devido ao impulso gerado por novas parcerias e operações. Ao longo dos anos 1990, iniciou-se um intenso debate a respeito da possibilidade de sua replicação na América Latina. Entidades como as Organizações das Nações Unidas para Alimentação e Agricultura (FAO), o Instituto Interamericano de Cooperação para a Agricultura (IICA) e o Banco Interamericano de Desenvolvimento (BID) passaram a insistir, com ênfase bastante normativa, na adoção desse enfoque. 
Ao todo foram lançadas três versões do programa: o Leaderl (1991-1993), restrito a regiões europeias consideradas de menor dinamismo econômico (Portugal, Espanha e Grécia); o Leader II (1994-1999), em continuidade ao anterior, mas com maior ênfase na necessidade de projetos inovadores; e o Leader+ (2000-2006), quando todos os territórios rurais da UE puderam acessar os recursos. A partir de 2007, a abordagem Leader foi incorporada aos programas de desenvolvimento rural de cada Estado-Membro da União Europeia, sendo financiado com recursos do Fundo Europeu Agrícola de Desenvolvimento Rural (Feader) e do orçamento de cada país (COLLE, 2017).

Nesse sentido, a partir do início dos anos 2000, começaram a ser operacionalizados dois programas que, de alguma maneira, auxiliaram na disseminação dessa estratégia em programas específicos em vários países da região: o programa Experiencias Piloto de Desarrollo Rural en América Latina (Expider), disseminado pelo BID; e o Projeto de Desenvolvimento Regional, desenvolvido pelo escritório regional da FAO para a América Latina e Caribe. Ambos faziam referência clara à sua inspiração na experiência da Iniciativa Leader e enfatizavam a identificação de métodos para o desenvolvimento rural adaptados às condições latino-americanas. Desde então, a América Latina têm se tornado um campo visado para a experimentação de programas de desenvolvimento rural com enfoque territorial (GHESTI, 2013; PERAFÁN, 2007).

Entretanto, apesar do entusiasmo inicial, essa disseminação encontrou pela frente alguns desafios bastante difíceis de serem solucionados unicamente com o instrumental do Leader, dada a complexidade que caracteriza o conjunto das dinâmicas sociais, políticas e econômicas na América Latina. Esse é o assunto a ser tratado a seguir.

\section{A fungibilidade do programa leader na América Latina}

Nesta seção são discutidas, com base nas sete categorias analíticas propostas por Rose (1993), as condicionalidades dessa tentativa de difundir nos países da América Latina o referencial europeu presente no Programa Leader. A partir do confronto entre comunalidades ou dissonâncias verificadas, ainda que de modo exploratório, foram levantados alguns aspectos qualitativos no sentido de um possível padrão de difusão de políticas públicas circunscrito ao contexto latinoamericano. Assim, mesmo sabendo das fortes assimetrias contextuais presentes nas experiências entre países diferentes na região, o foco foi problematizar o instrumental analítico escolhido a partir de uma manifestação mais geral dessa experiência de difusão de política. 


\section{Singularidade}

Um programa a ser transferido não precisa ser uma réplica exata de cada elemento da fonte original, desde que haja equivalências funcionais necessárias para sua implantação. No entanto, programas que se restringem a determinados lugares, como os destinados a prover assistência às famílias de agricultores, isto é, uma medida relacionada às especificidades das áreas rurais, seriam melhor definidos como programas "dependentes do contexto". Caso o contexto seja similar, esse tipo de programa, em princípio, pode ser transferível de um país para outro.

Mas embora um programa possa se tornar fungível pelo fato de tratar de problemas para os quais haja um paralelo entre várias jurisdições, a natureza do programa em questão pode exigir certas variáveis e ambientes contextuais para sua aplicabilidade. Caso tais "exigências" não sejam atendidas pelo novo arranjo político, ele pode se tornar único e, portanto, "infungível".

Dessa forma, a AT presente na iniciativa Leader - que surgiu para proporcionar aos países membros da UE uma espécie de laboratório para o desenvolvimento de capacidades locais e para a experimentação e difusão de lições a respeito de novas formas de satisfação das necessidades das comunidades rurais na União Europeia - pode ser considerada como uma estratégia dependente do contexto, o que requereria um conjunto de medidas complementares e adaptativas para sua difusão a outros contextos para além do europeu.

Uma de suas características importantes diz respeito às diretrizes locais de desenvolvimento por zona. A zona-alvo para a aplicação da política consiste em um território pequeno, homogéneo e socialmente coerente, frequentemente caracterizado por tradições comuns e um sentimento de pertencimento ou necessidades e expectativas compartilhadas. Como condição necessária, a localidade escolhida deve possuir coerência e recursos (humanos e econômicos) suficientes para formar a base de uma estratégia de desenvolvimento local viável. Tais recursos devem ser mobilizados e coordenados de modo a favorecer uma cultura participativa no território, com projetos que sejam capazes de induzir ações inovadoras, integradas e multissetoriais.

Nesse caso, não basta que o contexto territorial seja o mesmo para que ocorra a transferência de programas, isto é, tratar-se de áreas rurais e economias regionais; tornam-se necessários, ainda, outros elementos contextuais bastante específicos, o que tornaria a transferência de um programa baseado na AT algo que exige profunda atenção aos detalhes, dadas as singularidades que são exigidas para sua existência em seu local de origem. Por outro lado, em zonas com recursos paralelos em termos de singularidades, como aquelas relacionadas ao capital social de um território (ABRAMOVAY, 2000), um programa baseado na AT pode se tornar fungível. 
Portanto, além do desenho institucional de um programa em si, o contexto mais amplo para o qual ele é delineado deve ser levado em conta, pois pode lhe conferir um caráter singular que dificulta sua difusão.

\section{Instituições como meios necessários}

O termo instituições em lesson drawing tem um caráter mais restrito. Ele se refere às organizações formais do governo envolvidas na implementação e oferta de programas públicos. De acordo com Rose (1993), a fungibilidade de um programa depende do quanto ele exigirá em termos de estrutura institucional específica no país receptor ou se existe uma permutabilidade entre as instituições envolvidas. Há então a necessidade de se verificar se a jurisdição sobre a qual se pretende importar um programa possui as capacidades institucionais requeridas para recebê-lo.

Partindo de uma consideração bastante resumida, o cerne da AT presente na estratégia Leader se baseia em dois preceitos: construção de parcerias locais entre os setores público e privado; e abordagem ascendente de tomada de decisões. A princípio, esses preceitos não requerem nenhuma instituição específica para sua operacionalização. Nessa perspectiva, isoladamente das demais fatores, a AT pode se mostrar altamente fungível, pois, por sua generalidade neste aspecto em particular, poderia em tese se aplicar a qualquer caso concreto onde existam capacidades institucionais. Muito provavelmente, esse representa um dos fatores que têm facilitado o grande espraiamento de tal abordagem nos últimos anos em vários países latino-americanos, cada qual com seu enraizamento político característico.

Todavia, devido à sua complexidade, para essa abordagem as instituições per se constituem uma condição necessária para a consolidação bem-sucedida da AT, e o arranjo institucional criado para sua implementação torna-se um elemento fundamental para o sucesso da transferência de programas.

Retomando a categoria anterior, a AT exige elementos contextuais bastante específicos como condição necessária. Uma vez presentes esses elementos em uma localidade (território de incidência), um programa sob tal abordagem passa a ser dependente do contexto e, portanto, na sua transferência, as instituições constituem uma condição necessária para formar o ambiente exigido para sua incidência efetiva. Porém, não se constituem como condição suficiente, pois na falta desses elementos contextuais específicos, a AT se torna infungível quanto a seus efeitos ou consolidação. Dessa forma, a AT pode se mostrar altamente fungível no que diz respeito à forma (configuração institucional), mas, paradoxalmente, ser ao mesmo tempo infungível quanto ao conteúdo, pois depende de elementos contextuais bastante específicos e configurações institucionais bastante genéricas. 


\section{Recursos como restrição}

Políticas públicas, em geral, variam grandemente quanto a seu mix de recursos. Algumas podem ser intensivas em leis e regulação, outras, intensivas em dinheiro, e outras ainda podem ser intensivas tanto em trabalho quanto em dinheiro. A fungibilidade não requer que os recursos sejam idênticos, mas pelo menos equivalentes, pois a falta de um tipo específico de recurso pode se tornar um fator limitante de difícil solução. Por exemplo, a implementação de um programa exige uma quantidade mínima de dinheiro, e quanto maior for a demanda por esse recurso, menor será a capacidade das agências públicas em financiá-lo. Como alternativa, muitos programas são adotados através de estruturas já estabelecidas, o que reduz custos em termos de tempo, dinheiro e conhecimento para começar uma nova ação, além de se beneficiar de um quadro de servidores públicos já estabelecido e de procedimentos operacionais padronizados para os elementos que são comuns a muitas atividades governamentais.

No que tange à AT, o programa Leader foi introduzido como uma iniciativa comunitária financiada pelos fundos estruturais comunitários. Uma característica dessa iniciativa é o aumento substancial, não apenas na porcentagem de territórios em que a abordagem vem sendo aplicada, mas também no nível de financiamento atribuído aos projetos (CE, 2006). Acima de tudo, o retorno desse financiamento pode não ser contabilizado diretamente, e gerar frutos apenas no longo prazo.

Além de ser intensiva em dinheiro, a AT presente no programa Leader também o é em relação a recursos humanos. Retomando a segunda categoria, a construção de parcerias entre o setor público e o privado requer forte ênfase na construção de capacidades administrativas para estimular e apoiar a criação dos GALs. Ademais, a AT implica muitos elementos que não podem ser regulamentados ou exigidos por lei, abrangendo a esfera dos comportamentos individuais e coletivos que não podem ser "criados por decreto".

Portanto, no que diz respeito à estrutura de recursos, a transferência da AT para outro contexto diferente do europeu exige um exercício de vigilância epistemológica duplamente necessário. Primeiramente por causa do transplante da AT, que é referenciada a partir de uma perspectiva eurocêntrica; segundo, por causa da própria teoria (lesson drawing) que trata justamente da adequação ao contexto.

\section{Complexidade}

Em sua forma mais simples, um programa envolve um link direto entre uma única causa e um único efeito, do tipo: para alcançar $X$, então faça $A$. Por outro lado, um programa complexo envolve uma multiplicidade de causas operando direta e indiretamente para produzir outra multiplicidade de efeitos; ou seja, para alcançar 
$X$ e $Y$, então faça $A, B$ e C, que produzirão resultados indiretamente influenciados por $\mathrm{F}$ e $\mathrm{G}$, e assim por diante.

Dessa forma, um programa simples terá um “objetivo único", seja ele ambicioso ou pequeno. Por mais difícil que seja, será menos complexo do que perseguir três ao mesmo tempo, o que evita conflito entre metas concorrentes. Por sua vez, quanto menos numerosas e mais direitas forem as causas de um resultado almejado, maior será a probabilidade de fungibilidade de um programa, pois haverá pouco a ser transferido. Os programas mais simples se caracterizam, também, por possuir foco empírico, quer dizer, seus objetivos podem ser objetivamente verificados. Isso permite identificar o que um programa busca realizar e, consequentemente, avaliar a eficácia de sua transferência.

Por outro lado, a "familiaridade" em determinada área política simplifica o processo de lesson drawing. Quando a forma de um programa operar em uma jurisdição é bastante conhecida, a análise de sua transposição para outro contexto político se torna mais simples. Todavia, quando um determinado terreno político é ainda inexplorado, os resultados de uma experiência nesse campo tornam-se incertos, e quanto maior for a imprevisibilidade de um programa, mais difícil será tirar alguma lição sobre ele.

No que tange à AT, a abordagem Leader se caracteriza como uma metodologia que - devido a seu alto grau de generalidade, conforme ressaltado anteriormente, podendo se mostrar altamente fungível no que se refere à configuração institucional - não possui objetivos pré-determinados em abstrato, pois não representa um conjunto fixo de medidas a serem implementadas. Por isso, os objetivos e o foco dado à AT podem variar no mesmo sentido que as configurações institucionais nos casos concretos.

No entanto, apesar dos objetivos difundidos pela AT terem a liberdade de variar conforme o contexto de cada caso em particular, seus objetivos se mostram altamente complexos, com desdobramentos que implicam o correlacionamento de múltiplos objetivos específicos num todo coerente. Como causas para o desenvolvimento e ajustamento estrutural das regiões com atrasos de desenvolvimento, a abordagem Leader incentiva a reconversão econômica e social dessas regiões, bem como o desenvolvimento de novas atividades e fontes de emprego. Ela se resume em seis características principais que conformam um conjunto indivisível de ferramentas: i) estratégias locais de desenvolvimento por zona; ii) abordagem ascendente no que diz respeito à elaboração e execução de estratégias; iii) parcerias locais dos setores público e privado nos GALs; iv) ações integradas e multissetoriais; v) inovação; e, vi) cooperação. Essas características se complementam e interagem positivamente ao longo de todo o processo de 
implementação (CE, 2006). Nesse sentido, a abordagem Leader se apresenta bastante complexa em relação às causas de seus resultados almejados.

No que se refere a foco empírico, familiaridade e previsibilidade, a AT se mostra altamente genérica e abstrata, o que aumenta substancialmente sua complexidade e, em tese, deveria também diminuir sua fungibilidade. No entanto, o que se observa é justamente o oposto: a AT tem sido amplamente difundida por organismos multilaterais (FAO, BID, IICA e OCDE) de apoio e cooperação e adotada por diversos países latino-americanos, o que não necessariamente implica no sucesso em termos dos objetivos previstos com esses programas.

De acordo com Favareto (2010), muitos dos documentos produzidos pelos organismos multilaterais de cooperação constituem mais uma adição ao léxico dos formuladores das políticas do que a proposição de algo concreto. Muitas vezes falta uma verdadeira estratégia a sustentar o conjunto de considerações e proposições neles contidas. Embora esses documentos tentem aplicar um viés territorial a seus objetivos, o que se enuncia em suas considerações, instrumentos e orientações é um viés produtivista e setorial. Assim, apesar da grande difusão de estudos nessa área, o campo político da AT apresenta pouca familiaridade no contexto latino-americano.

Como consequência, o grau associado tanto à previsibilidade quanto à transferência da AT se torna baixo. Se até mesmo em um contexto como o europeu - onde a adoção da abordagem ascendente representa um requisito importante para os países europeus que pretendam se unir à UE - a implementação da AT não representa uma atividade trivial, quanto mais num contexto latino-americano, historicamente marcado por relações autoritárias de poder, baixa densidade democrática e forte heterogeneidade social.

\section{Escala de mudanças}

Normalmente, grandes mudanças são mais difíceis de serem alcançadas do que pequenas mudanças. Porém, inovação não se confunde com extensão de mudanças: a criação de um programa pode envolver uma pequena ou grande diferença em relação à demanda por recursos ou em relação a seus impactos.

Se a alteração recai sob um programa existente, como tratado anteriormente, é provável que a escala de mudanças seja minimizada. Nesse caso, embora possa haver alguma disputa política, provavelmente não haveria obstáculos técnicos a essa ação. O mesmo não ocorre quando há uma proposta de introdução de um programa novo a uma jurisdição. Trata-se de uma mudança em qualidade, pois a jurisdição terá, em primeiro lugar, que instituir os procedimentos que darão sustentação a esse programa. 
No contexto da UE, a abordagem Leader surgiu como um envolvimento gradual das comunidades locais no acréscimo de valor aos recursos locais, dando origem a uma abordagem ascendente por zona. O principal consenso resultante foi que os projetos de desenvolvimento rural seriam mais eficazes se fossem decididos e implementados pelos próprios agentes locais, acompanhados de procedimentos claros e transparentes, com o apoio das administrações públicas competentes e de assistência técnica necessária para a transferência de boas práticas. Com isso, a AT surgiu da convergência entre os países da UE em torno dos desafios e oportunidades oferecidos pela globalização às zonas rurais.

Nessa dinâmica, a partir do momento que diferenciação e agregação de valor passam a ser aspectos cruciais para os mercados de qualidade nos sistemas agroalimentares, os países desenvolvidos da Europa precisaram criar novas abordagens para que as políticas públicas estimulassem o desenvolvimento econômico, a inovação e o aumento da produtividade. Consequentemente, a ação do Estado passou a se caracterizar por uma maior descentralização e permeabilidade ao diálogo social no desenho e implementação de políticas públicas. Portanto, a AT emergiu como uma mudança incremental para o contexto europeu, e os países da UE evoluíram gradualmente nessa direção, construindo as condições endógenas necessárias.

Entretanto, retomando a segunda e a terceira categorias, essas condições endógenas, que irão constituir o "capital territorial" de cada região, são bastante específicas ao contexto europeu. Consequentemente, a transferência dessa AT para um contexto que não possua as condições necessárias se torna uma tarefa duplamente difícil: mais do que mudanças na superestrutura que requerem familiaridade no sentido de internalização de preceitos e conceitos, a AT exige elementos contextuais bastante específicos que são difíceis de serem imitados ou reproduzidos. Portanto, nessa situação em particular, a AT pressupõe uma mudança em qualidade com a construção de uma estrutura que dê sustentação à superestrutura almejada, e, se e somente se isso acontecer, é que se passa ao apoio aos atributos específicos dos territórios de incidência. A ordem dos fatores influencia os resultados, pois não é com uma simples mudança nas regras formais que se constrói uma infraestrutura que dê sustentação às instituições formais desejadas.

\section{Impacto da interdependência}

A interdependência existe quando um programa em uma jurisdição é influenciado por outros programas que abordam um problema correlacionado em outra jurisdição. Mesmo que os formuladores de políticas públicas ignorem o 
que se passa em outros lugares, em um sistema interdependente, os efeitos de um programa são o resultado das interações entre suas ações e as dos outros.

A globalização criou uma interdependência entre as políticas econômicas nacionais sem precedentes na história. Em um sistema aberto internacionalmente, cada economia nacional, além das suas próprias ações, fica sujeita ao resultado das medidas tomadas em outros países. Com isso, surge então um problema de governança global que motivou a criação de uma série de acordos, protocolos, tratados, grupos e redes entre países desenvolvidos e em desenvolvimento para a cooperação em temas econômicos e financeiros.

Na década de 1990, a proposta de governança territorial surgiu no âmbito do desenvolvimento rural da UE justamente como desenho de uma nova estrutura de governança, em resposta aos desafios e oportunidades impostos às áreas rurais pela globalização. Nesse contexto, redes ou associações de grupos Leader foram criadas ou emergiram de um modo mais informal a nível local, regional ou nacional. A ligação em rede abre espaço para o intercâmbio de resultados, experiências e saber-fazer entre comunidades locais, administrações e organizações envolvidas no desenvolvimento rural da UE, sejam ou não beneficiários diretos da estratégia.

No que se refere à transferência da AT para outros contextos, a fungibilidade dos impactos dessa abordagem (isto é, a criação de sinergias, uma propriedade material e imaterial comum e do capital social necessário ao aumento da competitividade econômica de áreas rurais) está relacionada não apenas à interdependência de um conjunto coeso de políticas públicas, mas, sobretudo, à superação do viés setorial em um sentido mais amplo, abrangendo tanto a esfera estatal como a da sociedade. Na esfera do Estado, para que os efeitos da AT sejam fungíveis, torna-se necessária uma abordagem holística ou sistêmica em detrimento de uma abordagem setorial ou fragmentada. Não basta, porém, que programas ou ações sejam reunidos em uma matriz e continuem a operar independentemente, mas que estejam coordenados num todo coerente interdependentemente. Essa é uma crítica comum apresentada, por exemplo, ao Programa Territórios da Cidadania, lançado no Brasil em 2009 (ver SILVA, 2013b).

Assim, para que a AT seja fungível em seus efeitos na promoção de um desenvolvimento sustentável, haveria a necessidade de associação de diferentes setores econômicos e sociais presentes em um território em torno de projetos coletivos e ações multissetoriais, com vistas a criar sinergias na produção de um bem comum ao território como um todo. Ou seja, diferentes programas e estruturas institucionais que já atuam em um contexto territorial específico precisariam estar inseridos no desenho de uma AT para que as ações previstas sejam de fato viáveis técnica, econômica e juridicamente. Isso envolve, portanto, o reforço do diálogo e 
da cooperação entre os diversos agentes locais, públicos e privados, na construção de uma "incidência territorial" específica para o programa ou política pública em questão (SILVA, 2014).

\section{Valores definindo objetivos}

Valores influenciam a atividade de lesson drawing somente quando são relevantes para a política em questão. A relevância atribuída a certos temas, particularmente por parte do eleitorado, pode proporcionar suporte para a adoção de uma lição, quando esta se apresenta e é vista como um meio válido para a realização de objetivos valorizados. Assim, qualquer lição consistente com valores consensuais irá receber apoio por parte de políticos de qualquer filiação partidária. Do contrário, os agentes políticos poderão impor restrições normativas (poder de veto).

Um ponto importante diz respeito à percepção dos formuladores de políticas públicas. Sejam quais forem suas razões determinantes, por exemplo, racionalidade limitada, a ideologia ou mesmo o oportunismo, tal percepção pode não corresponder ou não se "encaixar" em uma realidade objetivamente dada. Quando os agentes políticos examinam as lições em outras partes do mundo, sua percepção é seletiva, pois estão inclinados a ver o que gostariam de ver e a ignorar o que seja adverso, de modo que essa seletividade se combina também à adaptação seletiva às circunstâncias.

Os agentes políticos estão sujeitos a ter uma percepção não muito afinada com suas"reais" capacidades ou limitações institucionais, as quais, muitas das vezes, podem ser mais acuradamente percebidas por técnicos ou funcionários públicos, por lidarem no cotidiano com as questões práticas ou instrumentais de uma política pública. Ou seja, a desejabilidade política não costuma ser contrabalanceada pela viabilidade prática. Assim, apesar de um programa ser fungível por ir ao encontro dos anseios de uma coletividade, seja um pequeno grupo, uma elite política ou um grupo de pressão, não necessariamente resultaria que o programa fosse viável em termos práticos ou se consolidasse como uma instituição bem-sucedida.

No que se refere à transferência da AT para outros contextos, como o latinoamericano, o exercício de vigilância epistemológica se faz útil para a própria teoria que trata de sua adequação. Diferentemente da lógica dos países industrializados, os países latino-americanos ainda se encontram envoltos com muitos conflitos, incluindo aqueles pelo próprio direito ao território (SILVA, 2013a), o que faz com que uma ênfase especial dos recursos como restrição precisa ser colocada em evidência. A heterogeneidade sociocultural que permanece nos países da região dada a diversidade de valores que compõem as múltiplas identidades sociais que Ihe habitam - implica disputas pelo próprio conceito de desenvolvimento, o que 
torna mais custosa a construção de consensos e pactuações, sobretudo quando se compara com o contexto sociocultural mais homogêneo dos países europeus envolvidos na iniciativa Leader. Todavia, isso não implica dizer que não haja possibilidade de construção de consensos e projetos de interesse comum, apenas que há de se cuidar dessa questão extremamente relevante para o processo de difusão de políticas dessa natureza.

Outro ponto ainda a ser considerado é que - como debatido na terceira categoria - instituições e programas podem ser implementados através de outras estruturas já consolidadas, com fins de otimizar recursos (tempo, dinheiro e conhecimento) para sua implementação. Com isso, muitos valores e interesses presentes nas instituições anteriores podem "contaminar" as instituições nascentes, gerando uma herança que muitas vezes se torna um fator limitante (rigidez institucional) à capacidade inovativa do novo programa. Isso pode ocorrer porque as organizações representam um aglomerado de interesses políticos e de valores capazes de mobilizar oposição a uma determinada lição que seja inconsistente com seus interesses consolidados. Nesse caso, não seria então a forma institucional, mas a influência política que se constituiria num obstáculo à adoção de uma nova prática.

\section{Do lesson drawing ao espraiamento internacional de lições}

A questão essencial ao processo de policy transfer, conforme discutido até aqui a partir do arcabouço conceitual proposto por Rose (1993), diz respeito ao "encaixe" entre uma política e o ambiente institucional de acolhimento. Disso decorre a necessidade de um conhecimento suficientemente adequado não só da política escolhida, mas também do próprio ambiente que a receberá, em termos da adequação de seu perfil jurídico, político, social e econômico. Nesse caso, a tarefa crucial no processo de aprendizado político é a identificação das contingências que afetam a transferência política entre os diferentes contextos.

Com relação à concepção de um programa, as variáveis normativas ou políticas precisam estar alinhadas com as variáveis contextuais endógenas, ou seja, com as restrições técnicas e de recursos. Nessa perspectiva, para que uma transferência política seja bem sucedida, é necessário que haja uma sintonia "realista" entre a desejabilidade política e as capacidades e limitações institucionais de uma determinada configuração jurisdicional.

Por outro lado, o contexto institucional já existente estrutura as decisões posteriores, e as políticas adotadas no passado condicionam em alguma medida (no plano do pragmatismo político e do path dependence) as futuras. Assim, nos processos de transferência de políticas, as circunstâncias e a realidade de determinados locais, 
levando-se em consideração sua história, cultura e instituições relevantes, podem dar origem a adaptações diferentes das propostas originais. Há inclusive o risco de que uma "lição positiva" - quando adotada em resposta a uma possível alteração da posição e do peso social dos agentes portadores das novas e velhas instituições em um determinado contexto - possa vir a se tornar uma "lição negativa"; isto é, uma transferência desinformada, incompleta ou inapropriada, justamente pela falta de sintonia e adequação contextual por parte dos agentes portadores dessas instituições. Ocorre então a incorporação por adição de novos temas que não se fazem acompanhar das devidas mudanças institucionais capazes de sustentar a inovação que essa incorporação deveria significar. Ou seja, a ideia pode até ser válida, mas sua execução em uma determinada situação pode ser malconduzida.

Em linhas gerais, as restrições ao lesson drawing poderiam ser consideradas como "restrições normativas", exercidas pelos agentes políticos, e "restrições técnicas ou contextuais", exercidas pelas condições específicas da jurisdição importadora. Isto posto, este texto acrescenta uma pequena alteração à categoria de análise proposta por Rose (1993), ao colocar os recursos como "restrição em evidência", resultando na seguinte categoria: quanto mais alinhadas forem as variáveis normativas com as variáveis contextuais na concepção de um programa, mais fungível será a consolidação desse programa.

De acordo com a perspectiva proposta, uma determinada lição poderia se mostrar, ao mesmo tempo, fungível em termos normativos e "infungível" em termos técnicos. Nesse sentido, a fungibilidade "plena" - isto é, a fungibilidade de um programa per se acompanhada da fungibilidade da consolidação desse mesmo programa como uma instituição bem-sucedida - depende tanto da consistência entre os valores dos formuladores de políticas públicas e os valores de um programa, quanto da sintonia "realista" dessa consistência de valores com as capacidades e limitações institucionais de uma jurisdição.

Sob essa perspectiva derivam duas constatações importantes sobre a transferência da AT: i) uma lição pode ser altamente fungível no que diz respeito somente à sua forma; e ii) uma lição pode ser altamente fungível no que se refere à sua desejabilidade política.

Do exposto até agora, pode-se depreender que a fungibilidade de um programa, em alguns casos, pode não estar necessariamente associada à sua eficiência ou eficácia. Denominamos esse tipo de fungibilidade identificado neste texto de "espraiamento internacional de lições", ou seja, a disseminação de uma lição racionalmente atraente e justificável e, também, altamente generalizável a qualquer contexto institucional, mas dificilmente eficiente ou eficaz no que se refere à transferência do seu conteúdo. Um resultado a ser esperado de um processo 
dessa natureza é que a disseminação ocorrida sob essas condições tende a se tornar menos atrativa à medida que o tempo passa e suas contradições internas emergem, caso não seja planejada uma estratégia institucional de implementação que dialogue diretamente com o contexto específico do local a ser implementado.

Nessa dinâmica, com seu espraiamento generalizado, as ideias produzidas nos países de vanguarda se tornam hegemônicas ao serem propagadas por organismos multilaterais de cooperação internacional (EVANS, 2003), ocorrendo muitas vezes uma mera incorporação por adição ao léxico dos formuladores de políticas (FAVARETO, 2010). Com isso, ao mesmo tempo em que se legitimam no seu contexto de origem, essas ideias se tornam politicamente desejáveis em outras jurisdições, ao fomentarem, por vezes indiretamente, a idealização de um nivelamento a um patamar hegemônico ou um catch up rápido e fácil. No entanto, à medida que elas não se fazem acompanhar das capacidades materiais endógenas que dão sustentabilidade aos projetos criados simbioticamente às condições dos próprios países que os disseminam, tal estratégia passa a perder credibilidade no plano interno.

Supondo então que, em algum lugar no tempo, por qualquer motivo que seja, quando uma jurisdição se deixa seduzir pelos apelos do siren's call, num processo bastante assimilado ao lesson drawing em aparência, ocorreria uma lure, isto é, a adesão a um projeto politicamente desejável e facilmente adaptável no curto prazo, mas tecnicamente pouco viável a médio e longo prazos, pois não suportado pelas reais capacidades institucionais da jurisdição acolhedora. A partir do momento da adoção desse tipo de lição, gradualmente, a lure cede espaço a uma illusio, no sentido como Favareto (2010) a toma emprestada de Bourdieu, ou seja, a incorporação por adição de novos temas, sem a devida capacidade ou mudança institucional capaz de sustentar a inovação que ela deveria significar.

No entanto, a partir do momento em que os resultados envoltos por essa illusio passam a ser discutidos e a impor sua existência própria como um fato social, a médio e longo prazo, consequentemente, a infungibilidade dessa prática - da forma como foi debatido aqui - começa a "vir à tona". Isso se torna realidade à medida que suas diretrizes entram em contradição com as variáveis contextuais do novo cenário nacional no qual ocorre o processo de implementação, ou mesmo mudanças repentinas no ambiente político em países onde as condições de implementação dessas práticas ainda se encontravam frágeis e instáveis. Tal assunção fica, por fim, como uma nova proposta de problematizacao a ser verificada empiricamente no contexto das políticas recentes de desenvolvimento rural na América Latina. 


\section{Considerações finais}

Este trabalho procedeu a uma análise de aspectos do Programa Leader sensíveis e necessários de serem considerados em processos de transferência de políticas públicas. À luz do referencial teórico de policy transfer e lesson drawing, foi discutida a viabilidade do uso da abordagem territorial contida no programa europeu como referência normativa para a implementação de programas no contexto latino-americano.

Como principal contribuição, foi apresentado o conceito de "espraiamento internacional de lições", isto é, um tipo particular de fungibilidade de lições, que pode ser acrescentado às categorias analíticas propostas por Rose (1993). Nesse sentido, mesmo que sirvam como referência válida, os preceitos normativos difundidos pelo Programa Leader demandam uma ponderação sensata em relação às reais capacidades e limitações institucionais de determinada jurisdição.

Esse tipo especial de fungibilidade apresentado diz respeito à disseminação de uma lição racionalmente atraente e justificável e, também, altamente generalizável a qualquer contexto institucional. No entanto, deve-se ressalvar que isso não garante, por si só, que o contexto de acolhimento seja capaz de proporcionar uma sobrevida sustentável a essa lição, a qual pode se mostrar pouco eficaz quanto à transferência do seu conteúdo. Ela pode, com isso, tornar-se menos atrativa à medida que o tempo passa e suas contradições internas começam a aflorar.

O termo "espraiamento" denota aqui a ideia de um movimento de disseminação como uma onda: a propagação de uma lição que apresenta um ímpeto ou força inicial, mas que vai se esvaindo gradativamente com o passar do tempo, uma vez que sua base normativa difundida se choca com variáveis contextuais endógenas ao ambiente institucional acolhedor, devido a restrições técnicas e de recursos. Isso não implica, por sua vez, que qualquer processo de transferência internacional de políticas esteja condenado a essa sequência ilustrada pela difusão da abordagem territorial ao contexto latino-americano. Apenas se buscou ressaltar que processos institucionais dessa natureza são complexos e necessitam de uma condução bastante cuidadosa. Ou seja, além da difusão da estrutura normativa, deve-se pensar em ações complementares específicas a cada ambiente de acolhimento, as quais possam garantir ou criar os recursos (tanto materiais quanto humanos), as capacidades estatais e os marcos jurídicos necessários à implementação efetiva de uma estratégia territorial de desenvolvimento.

Por isso, as ponderações e reflexões advindas deste debate trazem contribuições analíticas não somente ao campo de estudos sobre difusão de políticas públicas, mas também aos próprios gestores governamentais, ao lançar luz sobre uma série de particularidades e restrições ao processo de transferência de políticas entre contextos institucionais distintos que precisam ser levados em conta pelos agentes responsáveis. 


\section{Referências bibliográficas}

ABRAmovaY, R. O capital social dos territórios. Revista Economia Aplicada, v. 4, n.2, 2000.

BISSELL, K.; LEE, K.; Freeman, R. Analysing policy transfer. International Journal of Tuberculosis and Lung Disease, v.15, n. 6, 2011.

CARVAlHo, Thales L. A reutilização de políticas pelo mundo: compreendendo os processos e a literatura sobre difusão/transferência de políticas públicas. Revista Fronteira, v.11, n. 21, 2012.

Ce - Comunidades EUROPEIAS. A abordagem Leader. Luxemburgo: Comunidades Europeias, 2006.

Colle, Celio A. Harmonização e complementaridade entre as políticas para a agricultura do Brasile da União Europeia. Porto Alegre: PUC/RS, 2017. Tese (Doutorado em Economia). Pontifícia Universidade Católica do Rio Grande do Sul, 2017.

Dolowitz, D. A policy-maker's guide to policy transfer. The Political Quarterly, 2003. DolowITZ, D.; MARSH, D. Who learns from whom: a review of the policy transfer literature. Political Studies, v. 44, n. 2, 1996.

Evans, P. Além da monocultura institucional. Revista Sociologias, Porto Alegre, v. 5, n. 9, 2003.

FAVARETO, A. A abordagem territorial do desenvolvimento rural-mudança institucional ou "inovação por adição"? Revista de Estudos Avançados, v. 24, n. 68, 2010.

GHESTI, J. P. A disseminação de políticas de desenvolvimento territorial rural na América Latina. Dissertação (Mestrado em Ciências Sociais). Universidade de Brasília, 2013.

Jouen, M. A Europa rural na viragem do terceiro milênio. Texto de Discussão. Observatório Europeu Leader, 2001.

LADI, S. Globalization, think-tanks and policy transfer. World Bank Conference of the Global Development Network, Bonn, Germany, 1999.

NEWMARK, A.J. An integrated approach to policy transfer and diffusion. Review of Policy Research, v.19, n. 2, 2002.

OCDE. The future of rural policy: from sectoral to place-based policies in rural areas. Paris: OCDE, 2003.

Perafán, M.E.V. O território do desenvolvimento e o desenvolvimento dos territórios. Brasília: UnB, 2007. Tese (Doutorado em Ciências Sociais). Universidade de Brasília, 2007.

ROSE, R. Lesson drawing in public policy. Chatham, UK: C.H. Publishers, 1993.

. Ten steps in learning lessons from abroad. Working Papers, European University Institute, n. 5, 2001.

SILVA, S.P. A abordagem territorial no planejamento de políticas públicas e os desafios para uma nova relação entre Estado e sociedade no Brasil. Cadernos Gestão Pública e Cidadania, São Paulo: FGV, v.17, n. 60, 2012.

Considerações analíticas e operacionais sobre a abordagem territorial em políticas públicas. In: Ipea. Brasil em desenvolvimento 2013. Brasília: Ipea, 2013a. 
Avanços e limites da implementação de políticas públicas nacionais sob a abordagem territorial no Brasil. Texto de Discussão, no 1898. Brasília: Ipea, 2013b. - Mediação social e incidência territorial de políticas públicas de desenvolvimento rural no Médio Jequitinhonha/MG. Cadernos Gestão Pública e Cidadania, São Paulo: FGV, v. 19, n. 65, 2014.

TORRES, F.; MACíAS, J.D. Hacia una política territorial del desarrollo rural de México. Convergencia-Revista de Ciencias Sociales, n. 50, 2009.

\section{João Paulo Ghesti}

Mestre em Ciências Sociais pelo Centro de Pesquisa e Pós-Graduação sobre as Américas (Ceppac) da Universidade de Brasília (UnB). Contato: joaoghesti@hotmail.com

\section{Sandro Pereira Silva}

Doutor em Políticas Públicas e Estratégia de Desenvolvimento pela Universidade Federal do Rio de Janeiro (UFRJ). Atualmente é Técnico de Planejamento e Pesquisa do Instituto de Pesquisa Econômica Aplicada (Ipea). Contato: sandroecbr@yahoo.com.br 